\title{
Three-dimensional chiropractor-patient contact loads during side posture lumbar spinal manipulation: a pilot study
}

Maruti Ram Gudavalli ${ }^{* *}$ and Robert M Rowell ${ }^{2}$

\begin{abstract}
Background: Patients with low back pain often seek chiropractic care and more than ninety percent of Chiropractors use lumbar side posture manipulation for the treatment of low back pain. During this procedure chiropractors deliver forces by means of hand contact on the patient in a side lying position. The objective of this pilot study was to report on the three-dimensional forces at the hand contact between the chiropractor and the simulated patient (asymptomatic volunteers) during side posture lumbar high velocity low amplitude adjustments.

Methods: In 2005, two licensed chiropractors delivered spinal manipulations to the lumbar spines of the participants. A three-dimensional force transducer (Model \# Mini-45, ATI-Industrial Automation, Apex, North Carolina) was used to measure the three-dimensional loads. The force-time histories were analyzed for preloads, peak loads, duration of thrusts to peak load, duration of thrust for completion, rate of loading, and magnitudes of the three forces and the resultant total force delivered by the chiropractor.
\end{abstract}

Results: The two chiropractors delivered a total of 14 thrusts to the five asymptomatic volunteers. Normal force (Fz) is the dominating force, followed by inferior-superior force (Fx). The lateral force (Fy) occurred in both directions.

Conclusions: This study reports on the three dimensional load (three forces and the total resultant force) characteristics of chiropractor-patient hand contact while delivering a chiropractic high velocity low amplitude (HVLA) manipulation in a side lying position.

Keywords: Manipulation, Biomechanics, Chiropractic, Low back, Spine, Low back pain

\section{Background}

Low back pain (LBP) is a major health problem to society in terms of cost and lost work days [1]. LBP will affect as many as $80 \%$ of US adults during their life [2]. The cost of LBP treatment in the US was estimated at $\$ 85$ billion in 2006 [3]. Patients with low back pain seek chiropractic care for pain relief and for return to normal activities. More than ninety percent of Chiropractors use lumbar side posture manipulation for the treatment of low back pain [4]. During this procedure a chiropractor delivers forces by means of hand contact on the patient in a side lying position. These forces are complex threedimensional forces and are delivered to create forces and

\footnotetext{
* Correspondence: Gudavalli_@@palmer.edu

'Biomechanics Core, Palmer Center for Chiropractic Research, 741 Brady street, Davenport, IA 52803, USA

Full list of author information is available at the end of the article
}

moments at the joint of interest thereby creating joint movements. This type of manipulation is defined as High Velocity Low Amplitude-Spinal Manipulation or HVLA-SM.

Much work has been done to quantify the forces delivered during chiropractic spinal manipulation (SM). The need for further research on the biomechanics of spinal manipulation has been identified in position papers $[5,6]$. Several investigators reported force-time profile characteristics during spinal manipulation for different regions of the spine [7-25]. Most of the studies measured only the normal force (defined by the perpendicular force to the back surface) characteristics of thrusting hand during the delivery of spinal manipulation [7-15,24]. All of these studies looked at the forces generated during SM of the cervical and thoracic spine, and the sacroiliac (SI) joint. These authors found that the peak and preload 


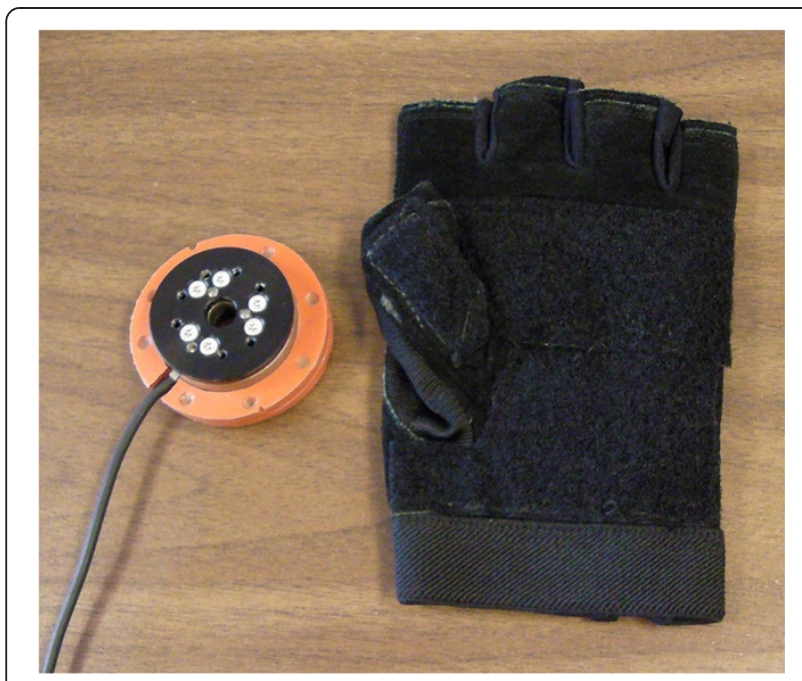

Figure $1 \mathrm{~A}$ photograph of the transducer and the glove used in this study.

forces were considerably smaller for HVLA-SM to the cervical spine compared with HVLA-SM to the thoracic spine. Kirstukas et al. [24] quantified forces delivered during unilateral thoracic manipulation using Tekscan pressure mats whereas other investigators [7-15] used Emed pressure sensors to measure pressure and convert it to force. All these studies reported on the preload force, peak force, thrust duration, and rates of loading from the force-time data collected while delivering the spinal manipulation. Triano et al. have done pioneering work on three dimensional (3-D) loads transmitted during spinal manipulation using an inverse dynamics approach with force plate embedded into the treatment table $[17-19,21,26]$. Van Zoest et al. were the first to report on a measurement method to quantify the three-dimensional forces at the chiropractor-patient hand contact $[27,28]$. These investigators reported on the 3-D forces during thoracic and sacro-iliac manipulations in the prone position. Their measurement did not include the moment loads at the hand contact.

The objective of this pilot study was to report on the three-dimensional forces at the hand contact between the chiropractor and the simulated patient (asymptomatic volunteers) during side posture lumbar high velocity low amplitude spinal manipulations.

\section{Methods}

This project was approved by the Palmer College of Chiropractic Institutional Review Board (IRB \# 2005G070). In 2005, informed consent was obtained from five participants with no symptoms of low back pain. The participants were a convenience sample of volunteers from our institution and consisted of 4 males and one female aged 22-51 years old. All participants were informed of the study details and signed the informed consent form. The chiropractors examined the participants for palpatory tenderness, spinal hypomobility, and any contraindication to spinal manipulation. The examination included history, vital signs, review of systems, an orthopedic examination, a brief neurological screen, and a spinal examination. Patients were excluded if contraindications to manipulation were found. Two licensed chiropractors evaluated the spinal segments for hypomobility using palpatory examination and delivered HVLA-SM to the lumbar spine of the participants in a side-lying posture. The participant was positioned in a side-lying (lateral recumbent) posture. The superior or free hip and knee were flexed and adducted across the midline. The chiropractor stabilized the participant by leaning his/ her own leg against the participant's superior leg, while holding the participant's superior shoulder. The

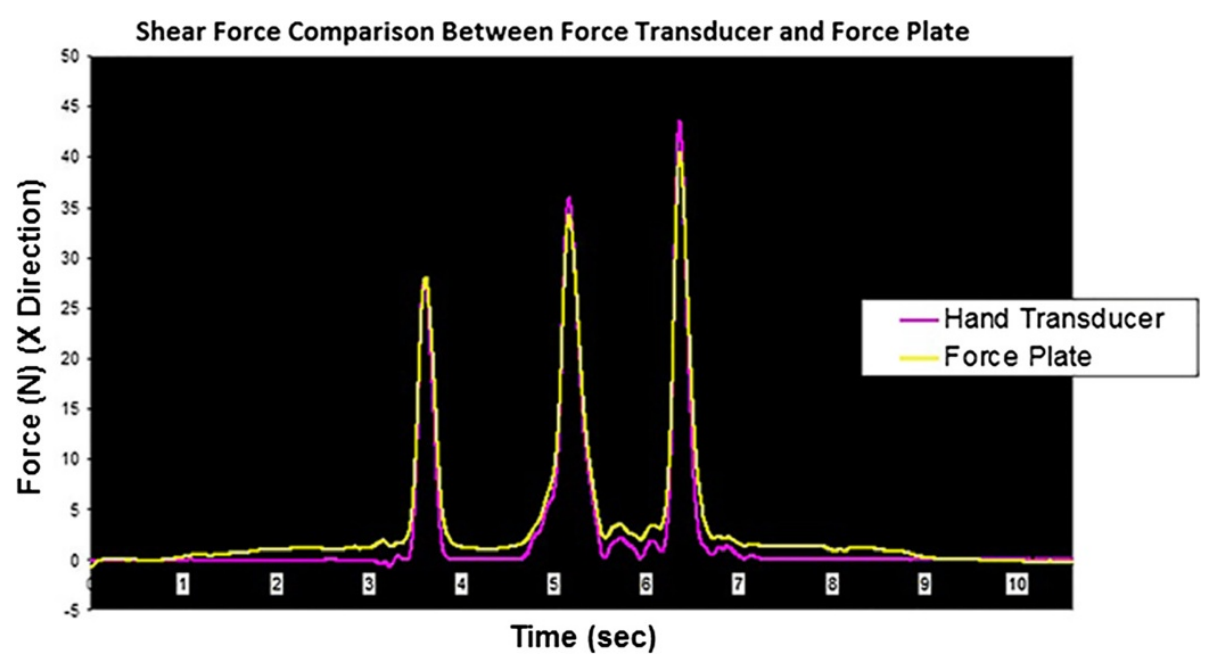

Figure 2 A typical graph comparing transducer and force plate measurements in shear. 


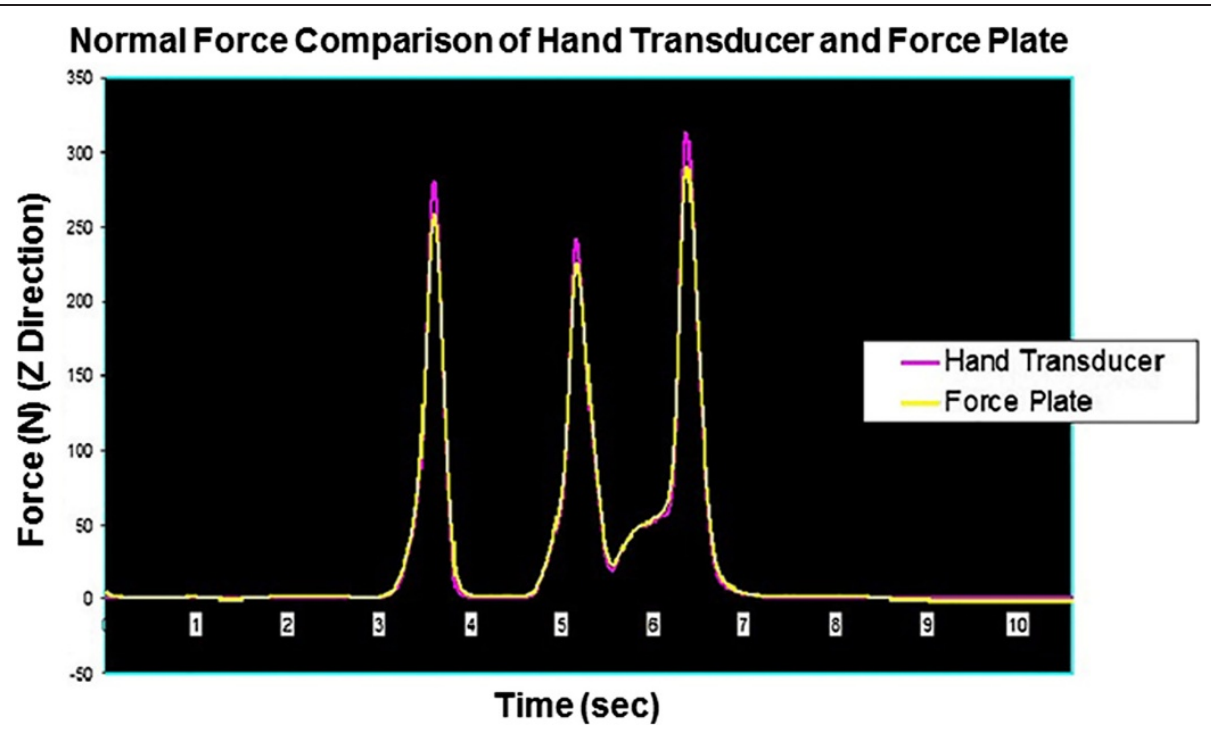

Figure 3 A typical graph comparing transducer and force plate measurements in normal force.

manipulation was applied with the chiropractor's hand by thrusting into the spine or sacroiliac joint. The thrusting load is a quick, short, controlled movement of the shoulder, arm and hand combined with a slight body drop.

A three-dimensional force transducer (Model \# Mini45, ATI-Industrial Automation, Apex, North Carolina) was used to measure the three-dimensional loads (three forces and the resultant total force) (see Figure 1). The transducer was placed between the chiropractor's hand (that was enclosed in a glove) and the participant's back. A thin layer of rubber padding was used between the transducer and the participant's back, and the transducer was attached to the chiropractor's glove using Velcro ${ }^{\circ}$ brand fasteners. The $\mathrm{X}$-axis was pointed superiorly on the spine, the Y-axis was pointing left laterally, and the Z-axis was pointing posteriorly normal to the back surface. The load-time histories were recorded at a sampling rate of $1000 \mathrm{~Hz}$ using custom written Lab View software and a laptop computer connected to the force transducer by means of a PCMCIA card (Keithly Instruments Inc.,Cleveland, Ohio). The transducer was tested to compare the accuracy of force measurements in normal direction as well as shear direction with a Bertec force plate and found to have good agreement (less than $3 \%$ differences) between both sensors (Figures 2 and 3).

The force-time histories were plotted using custom written MathCAD software (version 12, Parametric Technologies Corporation, Boston, Massachusetts) and to extract important parameters with user interface. With user interface the following parameters were extracted from the force-time graphs: Preload forces, peak forces, duration of preload, duration of thrusts to peak force, duration of unloading, total duration, rate of loading, and rate of unloading. The extracted data were then exported into an excel spreadsheet for further descriptive analysis using means and standard deviations.

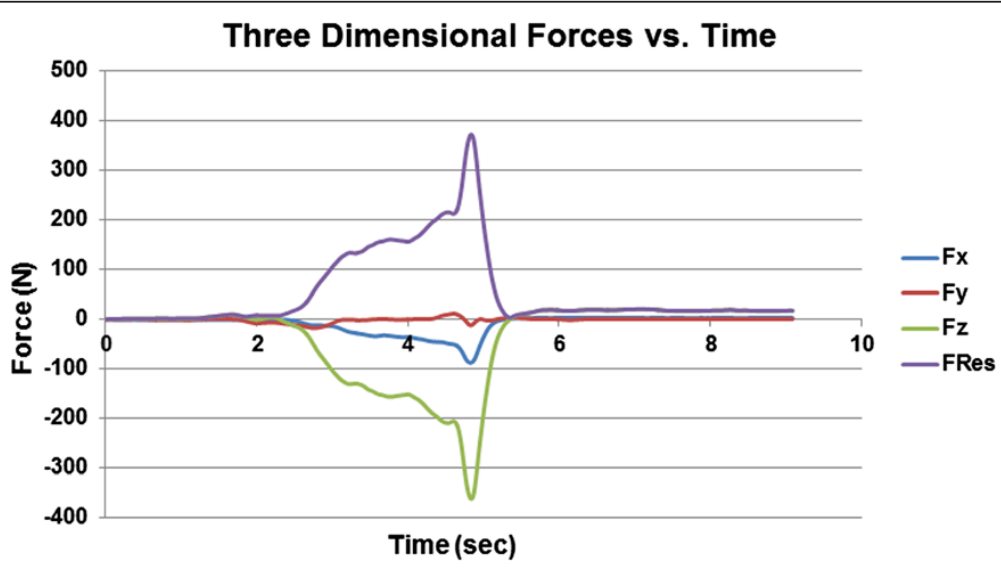

Figure 4 A typical 3-d force-time graphs during the side posture spinal manipulation. 


\section{Results}

Figure 4 shows typical force-time profiles of the three forces measured during the manipulation. Normal force which is perpendicular to the back surface is the dominant force applied by the chiropractor but shear forces (parallel to the back surface) were also observed.

The two chiropractors delivered a total of 14 thrusts to the five asymptomatic volunteers. Table 1 summarizes descriptively the 3-D forces, durations, and loading rates for all 14 spinal manipulations as well as for the two chiropractors. Normal force $(\mathrm{Fz})$ is the dominating force, followed by inferior-superior force $(\mathrm{Fx})$, and the lateral force $(\mathrm{Fy})$ which occurred in both directions.

\section{Discussion}

Van Zoest et al. were the first to report on a measurement method to quantify the three-dimensional forces at the chiropractor-patient hand contact $[27,28]$. Their study was restricted to three forces at the hand contact and only reported on the forces for thoracic and sacro-iliac spinal manipulations in the prone position. Our study expands to the lumbar spine, the measurement of 3-D forces at the chiropractor-patient interface during side posture lumbar spinal manipulation.
This study demonstrates that shear forces are present at the chiropractor's hand-patient interface while delivering treatments to the lumbar spine. These shear forces have distinct ranges for the two chiropractors. The chiropractor who delivered faster thrusts had higher shear force values. The average normal forces previously reported for sacro-iliac manipulations (222-228 N) were smaller compared to the present study $[27,28]$. Previous studies have also reported shear forces with large standard deviations similar to our study [27]. The average normal peak forces $(328 \mathrm{~N})$ reported on sacro-iliac joint manipulations on three participants by Herzog et al. are comparable to the normal forces measured in the present study [9].

Triano et al. reported on the transmitted 3-D loads to the spine using an inverse dynamics approach [17]. However, they did not report on the chiropractor-patient hand contact loads. The shear forces measured in the present study were smaller compared to the transmitted loads in the lumbar spine reported by Triano et al. using the inverse dynamics approach and force plate measurements [17].

The force measuring system developed and used in this study consisted of a laptop computer and was easily portable. The force-time graphs are displayed for

Table 1 Three-Dimensional spinal manipulation load characteristics

\begin{tabular}{|c|c|c|c|c|c|c|}
\hline \multirow[b]{2}{*}{$\mathrm{Fx}(\mathrm{N})$} & \multicolumn{2}{|c|}{ Both Chiropractors $(\mathrm{N}=14)$} & \multicolumn{2}{|c|}{ Chiropractor $1(\mathrm{~N}=6)$} & \multicolumn{2}{|c|}{ Chiropractor $2(\mathrm{~N}=8)$} \\
\hline & Mean & SD & Mean & SD & Mean & SD \\
\hline Preload & 14.6 & 7.1 & 19.4 & 4.9 & 11.1 & 6.5 \\
\hline Peak load & 25.3 & 37.5 & 61.8 & 26.2 & -2.1 & 10.6 \\
\hline \multicolumn{7}{|l|}{ Fy $(N)$} \\
\hline Preload & 4.8 & 9.3 & 7.4 & 9.2 & 2.8 & 9.5 \\
\hline Peak load & -20.6 & 40.2 & -40.4 & 51.7 & -5.8 & 22.4 \\
\hline \multicolumn{7}{|l|}{$\mathrm{Fz}(\mathrm{N})$} \\
\hline Preload & 96.4 & 30.7 & 71.5 & 22.8 & 115.1 & 21.0 \\
\hline Peak load & 335.3 & 71.3 & 382.2 & 37.7 & 300.1 & 71.5 \\
\hline \multicolumn{7}{|l|}{ FRes (N) } \\
\hline Preload & 98.7 & 29.3 & 75.5 & 20.9 & 116.1 & 21.7 \\
\hline Peak load & 340.3 & 75.2 & 392.6 & 41.0 & 301.0 & 72.0 \\
\hline Preload duration (ms) & 1966 & 1022 & 2976 & 524 & 1209 & 462 \\
\hline Thrust loading Duration(ms) & 164 & 37 & 144 & 26 & 179 & 39 \\
\hline Thrust unloading duration(ms) & 746 & 316 & 1046 & 211 & 521 & 134 \\
\hline Total duration(ms) & 2876 & 1240 & 4166 & 422 & 1909 & 482 \\
\hline Rateof Fz thrust loading(N/s) & 1577.9 & 733.8 & 2226.3 & 452.6 & 1091.6 & 472.3 \\
\hline Rate of Fz thrust unloading(N/s) & -517.4 & 203.6 & -384.5 & 119.9 & -617.1 & 200.6 \\
\hline Rateof FRes thrust loading(N/s) & 1595.1 & 749.8 & 2267.3 & 442.7 & 1090.9 & 475.7 \\
\hline Rate of FRes thrust unloading(N/s) & -522.7 & 201.9 & -394.5 & 121.3 & -618.8 & 201.4 \\
\hline
\end{tabular}

Fx-Inferior to superior force Fy- Lateral force Fz-Posterior-to-anterior force FRes-Resultant force.

$\mathrm{N}$-Newtons ms-milliseconds N/s- Newtons per second. 
viewing immediately after delivering the spinal manipulation. This system has the potential for taking it to any field clinicians' office to gather data and give immediate feedback on the forces delivered.

\section{Limitations and future directions}

The transducer is a two centimeter thick metal device with a rubber pad for the comfort of the participant. Unfortunately, tactile feedback is lost because of the transducer between the chiropractor's hand and patients back. Furthermore, this study had only 2 chiropractors and 5 asymptomatic volunteers. Future studies should aim at collecting data from more chiropractors and using more volunteers as well as low back pain patients. This is a preliminary study and provides the basis for such larger studies.

\section{Conclusions}

This study reports the three dimensional forces at chiropractor-patient hand contact while delivering a high velocity low amplitude (HVLA) manipulation. This is a preliminary study that showed there are shear forces applied at the chiropractor's hand-patient interface. Future studies should be directed in a systematic way on patients and with more chiropractors. These measurements have an important role in understanding the effects at the spinal joints that are being treated. These studies could also play an important role in the training of future chiropractors.

\section{Competing interests}

The authors declare that they have no competing interests.

\section{Authors' contributions}

MRG participated in the design of the study, carried out the biomechanical measurements, conducted the statistical analysis, and the drafting and revising of the manuscript. RMR participated in the design of the study and the drafting and revising of the manuscript. Both authors read and approved the final manuscript.

\section{Acknowledgments}

We would like to acknowledge the volunteers for their participation. This work was conducted in a facility constructed with support from Research Facilities Improvement Program Grant Number C06 RR15433-01 from the National Center for Research Resources, National Institutes of Health, Bethesda, Maryland.

\section{Author details}

${ }^{1}$ Biomechanics Core, Palmer Center for Chiropractic Research, 741 Brady street, Davenport, IA 52803, USA. ²Diagnosis and Radiology Department, Palmer College of Chiropractic, 1000 Brady street, Davenport, IA 52803, USA.

Received: 3 March 2014 Accepted: 25 July 2014

Published: 28 August 2014

\section{References}

1. Martin BI, Deyo RA, Mirza SK, Turner JA, Comstock BA, Hollingworth W, Sullivan SD: Expenditures and health status among adults with back and neck problems. JAMA 2008, 299:656-664.

2. Deyo RA, Weinstein JN: Low back pain. N Engl J Med 2001, 344:363-370.

3. Friedly J, Standaert C, Chan L: Epidemiology of spine care: the back pain dilemma. Phys Med Rehabil Clin N Am 2010, 21:659-677.
4. Christensen MG, Mark G, Kollash MW, Hyland JK: Practice Analysis of Chiropractic 2010: A project report, survey analysis, and summary of chiropractic practice in the United States. Greeley, Colorado: National Board of Chiropractic Examiners; 2010.

5. Brennan PC, Cramer GD, Kirstukas SJ, Cullum ME: Basic science research in chiropractic: the state of the art and recommendations for a research agenda. J Manipulative Physiol Ther 1997, 20:150-168.

6. Cramer G, Budgell B, Henderson C, Khalsa P, Pickar J: Basic science research related to chiropractic spinal adjusting: the state of the art and recommendations revisited. J Manipulative Physiol Ther 2006, 29:726-761.

7. Forand D, Drover J, Suleman Z, Symons B, Herzog W: The forces applied by female and male chiropractors during thoracic spinal manipulation. J Manipulative Physiol Ther 2004, 27:49-56.

8. Herzog W, Leonard TR, Symons B, Tang C, Wuest S: Vertebral artery strains during high-speed, low amplitude cervical spinal manipulation. J Electromyogr Kinesiol 2012, 22:740-746.

9. Herzog W, Conway PJ, Kawchuk GN, Zhang Y, Hasler EM: Forces exerted during spinal manipulative therapy. Spine 1993, 18:1206-1212.

10. Herzog W, Kats M, Symons B: The effective forces transmitted by high-speed, low-amplitude thoracic manipulation. Spine 2001, 26:2105-2110.

11. Herzog W, Zhang YT, Conway PJ, Kawchuk GN: Cavitation sounds during spinal manipulative treatments. J Manipulative Physiol Ther 1993 16:523-526

12. Herzog W: The Mechanical Neuromuscular, and Physiologic Effects Produced by Spinal Manipulation. In Clinical Biomechanics of Spinal Manipulation. Edited by Herzong W. New York: Churchill Livingstone; 2000:191-207.

13. Hessell BW, Herzog W, Conway PJ, McEwen MC: Experimental measurement of the force exerted during spinal manipulation using the Thompson technique. J Manipulative Physiol Ther 1990, 13:448-453.

14. Kawchuk GN, Herzog W, Hasler EM: Forces generated during spinal manipulative therapy of the cervical spine: a pilot study. J Manipulative Physiol Ther 1992, 15:275-278.

15. Kawchuk GN, Herzog W: Biomechanical characterization (fingerprinting) of five novel methods of cervical spine manipulation. J Manipulative Physiol Ther 1993, 16:573-577.

16. Triano JJ: The Mechanics of Spinal Manipulation. In Clinical Biomechanics of Spinal Manipulation. Edited by Herzog W. New York: Churchill Livingstone; 2000:92-190.

17. Triano J, Schultz AB: Loads transmitted during lumbosacral spinal manipulative therapy. Spine 1997, 22:1955-1964.

18. Triano JJ, Rogers CM, Combs S, Potts D, Sorrels K: Developing skilled performance of lumbar spine manipulation. J Manipulative Physiol Ther 2002, 25:353-361.

19. Triano JJ, Rogers CM, Combs S, Potts D, Sorrels K: Quantitative feedback versus standard training for cervical and thoracic manipulation. $J$ Manipulative Physiol Ther 2003, 26:131-138.

20. Triano JJ, Gissler T, Forgie M, Milwid D: Maturation in rate of high-velocity, low-amplitude force development. J Manipulative Physiol Ther 2011, 34:173-180

21. Triano JJ, Scaringe J, Bougie J, Rogers C: Effects of visual feedback on manipulation performance and patient ratings. J Manipulative Physio/ Ther 2006, 29:378-385.

22. DeVocht JW, Owens EF, Gudavalli MR, Strazewski J, Bhogal R, Xia T: Force-time profile differences in the delivery of simulated toggle-recoil spinal manipulation by students, instructors, and field doctors of chiropractic. J Manipulative Physiol Ther 2013, 36:342-348.

23. Gudavalli MR, DeVocht J, Tayh A, Xia T: Effect of sampling rates on the quantification of forces, durations, and rates of loading of simulated side posture high-velocity, low-amplitude lumbar spine manipulation. J Manipulative Physiol Ther 2013, 36:261-266.

24. Kirstukas SJ, Backman JA: Physician-applied contact pressure and table force response during unilateral thoracic manipulation. J Manipulative Physiol Ther 1999, 22:269-279.

25. Colloca CJ, Cunliffe C, Pinnock MH, Kim YK, Hinrichs RN: Force-time profile characterization of the McTimoney toggle-torque-recoil technique. J Manipulative Physiol Ther 2009, 32:372-378.

26. Triano JJ, Descarreaux M, Dugas C: Biomechanics-review of approaches for performance training in spinal manipulation. $J$ Electromyogr Kinesiol 2012, 22:732-739. 
27. van Zoest GG, Gosselin G: Three-dimensionality of direct contact forces in chiropractic spinal manipulative therapy. J Manipulative Physiol Ther 2003, 26:549-556.

28. van Zoest GG, van den Berg HT, Holtkamp FC: Three-dimensionality of contact forces during clinical manual examination and treatment: a new measuring system. Clin Biomech 2002, 17:719-722

doi:10.1186/s12998-014-0029-4

Cite this article as: Gudavalli and Rowell: Three-dimensional chiropractor-patient contact loads during side posture lumbar spinal manipulation: a pilot study. Chiropractic \& Manual Therapies 2014 22:29.

\section{Submit your next manuscript to BioMed Central and take full advantage of:}

- Convenient online submission

- Thorough peer review

- No space constraints or color figure charges

- Immediate publication on acceptance

- Inclusion in PubMed, CAS, Scopus and Google Scholar

- Research which is freely available for redistribution 